\title{
O paciente com câncer e a espiritualidade: revisão integrativa
}

\author{
Cancer Patients and Spirituality: An Integrative Review \\ El paciente con cáncer y la espiritualidad: una revisión integrativa
}

Como citar este artigo:

Silva, Daniel Augusto da. O paciente com câncer e a espiritualidade: revisão integrativa. Revista Cuidarte. 2020;11(3):e1107. http://dx.doi.org/10.15649/cuidarte.1107

\section{Revista Cuidarte Rev Cuid. 2020; 11(3): e1107}

doi) $h$ ttp://dx.doi.org/10.15649/cuidarte.1107

E-ISSN: 2346-3414

(1) Daniel Augusto da Silva
1 Fundação Educacional do Município de Assis (FEMA). Assis (SP), Brasil. Autor de Correspondência. E-mail daniel.augusto@unifesp.br

\section{Resumo}

Introdução: A magnitude do câncer permite a afirmação de que se trata de um problema de saúde pública, com altas taxas de incidência, prevalência e mortalidade na população, com estimativa de 27 milhões de casos novos em 2030. Nesta situação, o enfrentamento pode se dar com o uso de diferentes estratégias e dentre elas, o predomínio da religiosidade e espiritualidade é evidente. O objetivo é compreender as interferências ocorridas na vida de pacientes com câncer e as mudanças de comportamento como consequência de seu envolvimento com a espiritualidade. Materiais e métodos: Revisão integrativa composta de dez artigos, com busca realizada por meio da Biblioteca Virtual da Saúde, e utilização dos Descritores de Saúde: Neoplasias e Espiritualidade. Resultados: A experiência do câncer pode ser geradora de sentimento de culpa, tristeza, fracasso, perda de autoestima, incerteza, ansiedade, depressão, nervosismo, medo, preocupação e insegurança quanto aos futuros acontecimentos, pois, mesmo com o avanço tecnológico, estes ainda são significados atribuídos ao câncer, o que propicia a intensificação pela busca pela espiritualidade. Discussão: A religiosidade e a espiritualidade podem se constituir como importantes estratégias de enfrentamento, pois constituem fontes de conforto e esperança diante de um momento desafiador. Conclusão: O paciente com câncer que vivencia a espiritualidade como instrumento terapêutico é independente de sexo, idade, classe social, raça e religião, sendo que a afirmação da importância do apego espiritual se mostrou de forte impacto positivo na vida destes pacientes.

Palavras chave: Pacientes; Neoplasias; Espiritualidade; Terapêutica.

Recibido: diciembre 23 de 2019

Aceito: mayo 22 de 2020

Publicado: septiembre 1 de 2020 $\square *$ Correspondência

Daniel Augusto da Silva

E-mail:daniel.augusto@unifesp.br 


\section{Cancer Patients and Spirituality: An Integrative Review}

\section{Abstract}

Introduction: The magnitude of cancer suggests that it is a public health problem with high incidence, prevalence and mortality rates in the population, averaging 27 million new cases by 2030. Different coping strategies are used to face this situation, in which religiosity and spirituality are clearly predominant. Objective: To understand the changes in the lives of cancer patients and their behavior as a consequence of their spiritual practice. Materials and methods: An integrative review study comprising ten articles was conducted, which were obtained from the Virtual Health Library using the descriptors neoplasm and spirituality. Results: Experiencing cancer may cause feelings of guilt, sadness, failure, loss of self-esteem, uncertainty, anxiety, depression, nervousness, fear, concern and insecurity about the future because, despite today's technological advances, such feelings continue to be attributed to cancer, intensifying the search for spirituality. Discussion: Religion and spirituality can be seen as important coping strategies providing comfort and hope in difficult times. Conclusion: Cancer patients experiencing spirituality as a therapeutic tool is not dependent on gender, age, social class, race and religion as well as the importance of spiritual practice has been proved to have a strong positive impact on the lives of cancer patients.

Key words: Patients; Neoplasms; Spirituality; Therapeutics.

\section{El paciente con cáncer y la espiritualidad: una revisión integrativa}

\section{Resumo}

Introducción: La magnitud del cáncer permite afirmar que se trata de un problema de salud pública con altas tasas de incidencia, prevalencia y mortalidad en la población, con unos 27 millones de nuevos casos estimados para 2030. Para afrontar esta situación se usan diferentes estrategias en las que es evidente el predominio de la religiosidad y la espiritualidad. Objetivo: Comprender los cambios en la vida de los pacientes con cáncer y en su comportamiento como consecuencia de su práctica espiritual. Materiales y métodos: Se trata de un estudio tipo revisión integrativa compuesto por diez artículos que se obtuvieron a través de la Biblioteca Virtual de Salud con dos descriptores de salud: neoplasias y espiritualidad. Resultados: La experiencia del cáncer puede generar sentimientos de culpa, tristeza, fracaso, pérdida de autoestima, incertidumbre, ansiedad, depresión, nerviosismo, miedo, preocupación e inseguridad respecto a eventos futuros, porque, incluso con el avance tecnológico actual, tales sentimientos siguen siendo atribuidos al cáncer. lo que intensifica la búsqueda de la espiritualidad. Discusión: La religión y la espiritualidad pueden considerarse como estrategias de afrontamiento importantes, ya que son formas de consuelo y esperanza ante los momentos difíciles. Conclusión: El paciente con cáncer que experimenta la espiritualidad como herramienta terapéutica es independiente del género, edad, clase social, raza y religión, así como la importancia de la práctica espiritual ha demostrado tener un fuerte impacto positivo en la vida de estos pacientes.

Palabras clave: Pacientes; Neoplasias; Espiritualidad; Terapéutica. 


\section{Introdução}

Entre as doenças crônico-degenerativas, o câncer tem posição de destaque devido a crescente taxa de mortalidade a cada ano. No mundo, em 2018, ocorreram 18,1 milhões de novos casos e 9,6 milhões de óbitos por câncer ${ }^{1}$. No Brasil, 600.000 novos casos de câncer são estimados pelo Instituto Nacional do Câncer para o ano de 2018, e esta projeção também é válida para o ano de 2019. Destaca-se que havia estimativa de 580.000 casos novos no biênio 2016-20172-3.

Define-se o câncer como um tumor maligno, um conjunto de mais de 100 patologias, e não uma única doença. $O$ crescimento descontrolado de células anormais, também chamadas de malignas, é uma característica desta patologia. Pode ocorrer invasão de órgãos e tecidos adjacentes envolvidos, e ainda existe a possibilidade de disseminação para outras regiões do corpo, a essa disseminação, dá-se o nome metástase ${ }^{4}$.

Múltiplas causas podem ser atribuídas ao câncer, podendo ser externas ou internas ao organismo, com inter-relação entre elas. O meio ambiente, os hábitos ou costumes característicos de um ambiente social e cultural são relacionadas as causas externas do câncer, enquanto que, na maioria das vezes, as causas internas são geneticamente pré-determinadas, e se ligam à capacidade de defesa do organismo frente as agressões externas. Fatores ambientais associam-se de 80 a $90 \%$ dos casos, e são conhecidos e disseminados na sociedade, como a associação do cigarro ao câncer de pulmão, a exposição excessiva ao sol e a associação ao câncer de pele, alguns vírus e a leucemia. Alguns outros fatores, como componentes alimentares, estão em estudo, e outros muitos ainda são completamente desconhecidos. A intensidade e duração da exposição das células aos agentes causadores de câncer são comportamentos influenciadores para o surgimento do câncer, sendo que, quanto maiores, mais vulnerável a pessoa está para o surgimento desta patologia 4 .

Diferentes estratégias de enfrentamento são utilizadas por pessoas frente a condição de diagnóstico de câncer, e o predomínio da religiosidade e da espiritualidade nesta população é evidente.

Esforços e avanços tecnológicos instrumentalizam o tratamento do câncer, e possibilitam a cura de muitos tipos de neoplasias malignas, contudo, o estigma social da inexistência da cura, que remete ao medo e angústia relacionados a dor, mutilação, deformidade e morte ainda são presentes frente ao diagnóstico de câncer ${ }^{5}$.

Diferentes estratégias de enfrentamento são utilizadas por pessoas frente a condição de diagnóstico de câncer, e o predomínio da religiosidade e da espiritualidade nesta população é evidente ${ }^{7}$.

Muitos estudos têm sido realizados relacionados ao câncer, todavia, ainda com todos os avanços já ocorridos, o desconhecimento da causa do câncer permanece em muitas vezes, e ainda vivenciamos a não total eficiência dos tratamentos realizados a pacientes com diagnóstico de câncer. Neste cenário de vivência, estes pacientes são vulneráveis a apresentar os mais diversos sentimentos desde o momento da descoberta do diagnóstico, e até mesmo durante o tratamento ${ }^{6}$.

Derivada do termo spiritus, espiritualidade significa "sopro de vida". Possibilita que às pessoas questionem, procurem e encontrem o sentido da sua vida, sendo que este pode ocorrer de formas variadas, caracterizando a espiritualidade de forma individual, dinâmica e subjetiva, pois é influenciada pela afinidade entre a pessoa e o ser superior com o qual se relaciona ${ }^{8-9}$. 
O medo da morte é vivenciado por pacientes diagnosticados com câncer, e o comportamento frente ao processo de adoecimento pode se manifestar de diversas formas e estágios, compreendendo a negação parcial ou total doença, ira/revolta, barganha, depressão e aceitação ${ }^{10}$.

Ao se deparar com essas questões, a situação pode colaborar na busca por alívio do sofrimento, ou do problema, e neste contexto, o apego espiritual poderá ser inserido.

O apego espiritual é essencial para o tratamento de doenças crônicas, como o câncer, que é, para a grande maioria, causador de intenso estresse emocional, doença física e morte. O apego espiritual proporciona a busca de sentido para os acontecimentos, respostas para as questões da vida, a integridade, a paz, a harmonia e a individualidade ${ }^{11}$.

O apego espiritual proporciona a busca de sentido para os acontecimentos, respostas para as questões da vida, a integridade, a paz, a harmonia e a individualidade.

O câncer, pelo estigma social ligado à morte e ao sofrimento, constitui-se em momento de grande procura e dedicação às questões espirituais por parte dos pacientes, como instrumento para busca do conforto através da fé, que lhe proporcione sentido de vida e de morte, e paz. Sentimentos de esperança, amor e fé são evidenciados quando o envolvimento sadio junto a espiritualidade ocorre, e pode ser observado em pessoas de todas as faixas etárias, englobando pacientes e até familiares ${ }^{12-13}$.

A fé, portanto, é entendida como importante fenômeno existencial, não havendo possibilidades para separação do ser humano, por envolver vontade, emoções, desejos e atitudes como aspectos da personalidade do sujeito que crê, superando o cognitivo. Principalmente em momentos de crise e/ou adoecimento, a fé é essencial. Diferencia-se da razão pela característica objetiva que esta apresenta ${ }^{14}$.

A literatura não fornece consenso sobre o conceito de religiosidade e de espiritualidade, por vezes sendo utilizadas como um mesmo significado, todavia, uma diferença clara se refere ao sistema de adoração e doutrina que compõe somente às questões religiosas ${ }^{15}$. Neste sentido, entende-se a religiosidade como a forma que a fé é empregada, por meio da adesão a uma religião e seguimento aos preceitos de uma instituição religiosa organizada ${ }^{\text {. }}$

É importante observar que os pacientes, nas situações já descritas nos parágrafos anteriores, estão vulneráveis e se dedicam com maior ênfase às questões religiosas, espirituais e as crenças pessoais, e, dessa forma, torna-se necessário que essas questões sejam consideradas na prática clínica profissional de saúde, afim de que ocorra garantia de estabelecimento de tratamento holístico e integrativo ${ }^{16}$.

A proposta para a realização deste trabalho justifica-se pela importância de compreender a relação entre as questões espirituais e a experiência do adoecer com câncer. Desta forma, este estudo tem o objetivo de compreender as interferências ocorridas na vida de pacientes com câncer e as mudanças de comportamento como consequência de seu envolvimento com a espiritualidade.

\section{Materiais e métodos}

Trata-se de um estudo de revisão integrativa da literatura. As etapas que compõem o método de revisão integrativa são: estabelecer a hipótese ou a pergunta da revisão; selecionar a amostra 
a ser estudada; categorizar os estudos; analisar os estudos inclusos na pesquisa; interpretar os resultados e apresentar a revisão ou a síntese do conhecimento ${ }^{17}$. Para este estudo, a questão norteadora foi: Quais as relações entre questões espirituais e as experiências do diagnóstico e tratamento de pacientes com câncer?

Como revisão integrativa da literatura, população estudada constitui-se de artigos publicados e disponibilizados pela Biblioteca Virtual em Saúde, que abriga as bases de dados LILACS (Literatura Latino-Americana e do Caribe em Ciências da Saúde); BDENF (Base de Dados de Enfermagem); MEDLINE (Literatura Internacional em Ciências da Saúde); e CINAHL (Cummulative Index to Nursing and Allied Health Literature). A busca de artigos na Biblioteca Virtual de Saúde foi realizada em setembro de 2019, utilizando-se os Descritores de Saúde: Neoplasias; Espiritualidade.

Os critérios de inclusão para seleção da amostra de artigos foram: artigos que abordassem a interferência da religiosidade / espiritualidade no paciente com câncer sob a perspectiva do próprio paciente, indexados nas bases de dados selecionadas para o estudo e publicados no período de 2008 a 2018, em português. Os critérios de exclusão foram: artigos completos indisponíveis, artigos de revisão de literatura, integrativa ou sistemática, dissertações e teses. A busca e a seleção dos artigos basearam-se no The Strengthening the Reporting of Observational Studies in Epidemiology (STROBE). Os procedimentos de busca e número de artigos analisados são apresentados na Figura 1.

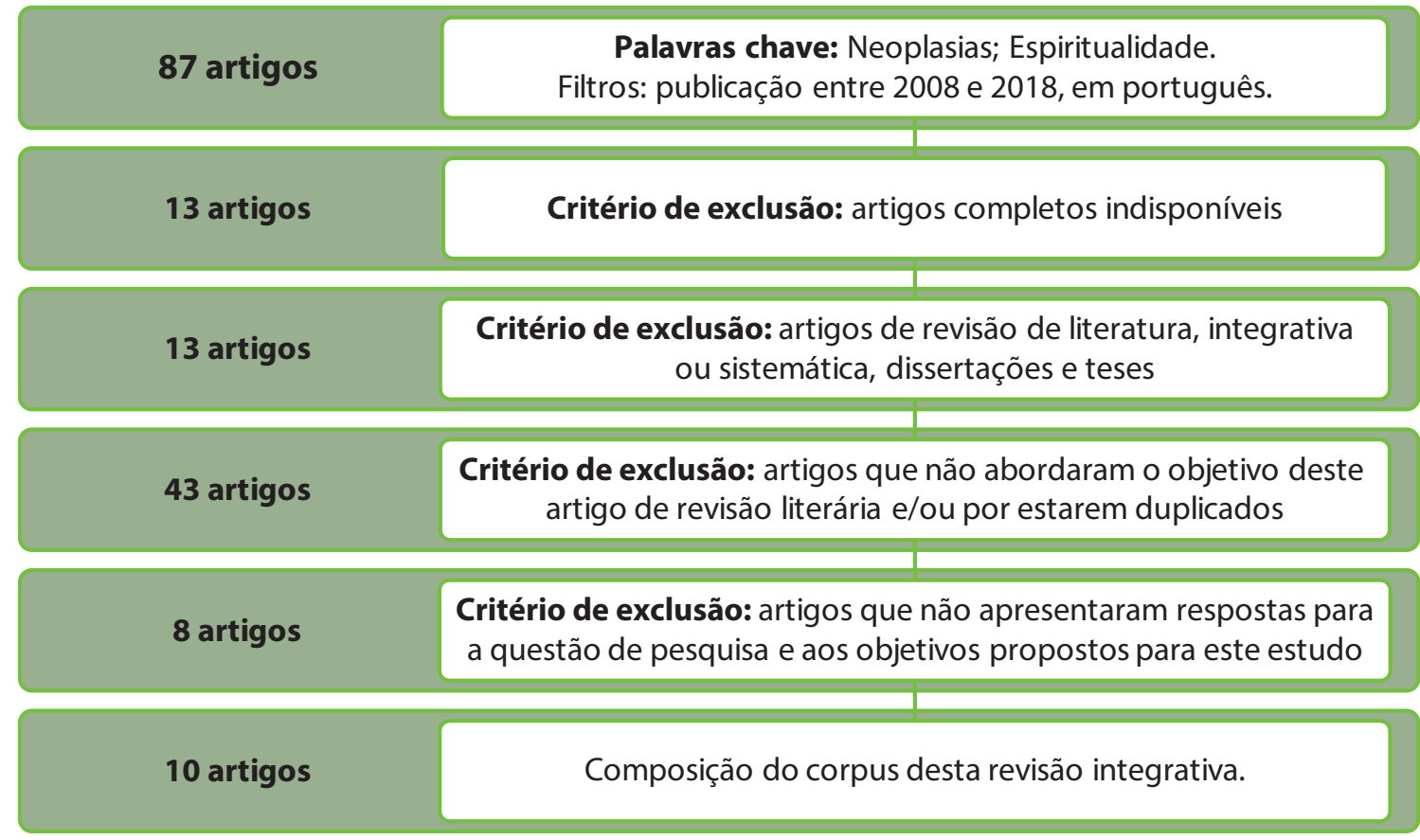

Figura 1. Procedimentos de busca e total de artigos analisados. Assis, SP, Brasil, 2020

Para viabilizar a análise dos artigos que integraram a revisão de literatura, foi utilizado um formulário de coleta de dados, com itens que contemplaram os objetivos do estudo.

O processo de análise envolveu a leitura e releitura dos artigos e o preenchimento do formulário com dados de todos os artigos. Em seguida, os dados foram analisados tendo como base seus conteúdos, além da relação dos dados com o objeto de interesse destacados em cada estudo. 


\section{Resultados}

Houve a agregação de dez artigos que atenderam aos critérios para inclusão propostos para esta revisão de literatura. Conforme explicitado no capítulo anterior, para esta revisão foi construído, pelos autores, um instrumento para coleta de dados. Esses dados são demonstrados compreendendo cada artigo selecionado e as informações respectivas Tabela 1.

Tabela 1. Apresentação da síntese de artigos incluídos na revisão integrativa. Assis, SP, Brasil, 2020

\begin{tabular}{|c|c|c|c|c|c|c|}
\hline $\begin{array}{l}\text { Autores/Ano/ } \\
\text { Método }\end{array}$ & $\begin{array}{l}\text { População } \\
\text { do estudo }\end{array}$ & $\begin{array}{l}\text { Sentimentos e } \\
\text { afetações no } \\
\text { diagnóstico de } \\
\text { câncer }\end{array}$ & $\begin{array}{l}\text { Sentimentos e } \\
\text { afetações duran- } \\
\text { te o tratamento } \\
\text { do câncer }\end{array}$ & $\begin{array}{l}\text { A espiritualidad } \\
\text { e e a decisão pe- } \\
\text { lo enfrentamen- } \\
\text { to do câncer }\end{array}$ & $\begin{array}{l}\text { Ações } \\
\text { desenvolvidas } \\
\text { no campo } \\
\text { espiritual }\end{array}$ & $\begin{array}{l}\text { A espiritualidade } \\
\text { e a busca pela } \\
\text { cura }\end{array}$ \\
\hline $\begin{array}{l}\text { Menezes et } \\
{\text { al., } 2018^{18}} \\
\text { Quantitativo, } \\
\text { com aplicação } \\
\text { do EORTC } \\
\text { QLQ - C30 e } \\
\text { WHOQOL - } \\
\text { SRPB. }\end{array}$ & $\begin{array}{l}42 \text { pessoas, } \\
\text { com idade } \\
\text { entre } 40 \text { e } 99 \\
\text { anos. } \\
\text { Cânceres } \\
\text { mais } \\
\text { frequentes: } \\
\text { próstata, } \\
\text { mama, pele, } \\
\text { leucemia. }\end{array}$ & $\begin{array}{l}\text { Sete descon- } \\
\text { heciam ou } \\
\text { negavam o } \\
\text { diagnóstico. } \\
\text { Uma paciente } \\
\text { afirmou que a } \\
\text { família } \\
\text { não tinha } \\
\text { conhecimento } \\
\text { da doença. }\end{array}$ & $\begin{array}{l}\text { Câncer afetou } \\
\text { a tríade corpo, } \\
\text { mente e } \\
\text { espírito. Gerou } \\
\text { desconfortos } \\
\text { físicos, } \\
\text { emocionais, } \\
\text { espirituais, } \\
\text { econômicos e } \\
\text { sociais. }\end{array}$ & $\begin{array}{l}\text { Todos os } \\
\text { participantes } \\
\text { referiram Deus } \\
\text { e sua fé como } \\
\text { apoio } \\
\text { fundamental. }\end{array}$ & $\begin{array}{l}\text { Não apontou } \\
\text { ações no } \\
\text { campo } \\
\text { espiritual. }\end{array}$ & $\begin{array}{l}\text { A espiritualida- } \\
\text { de, religiosida- } \\
\text { de e crenças } \\
\text { pessoais são } \\
\text { utilizadas } \\
\text { como } \\
\text { ferramentas de } \\
\text { experiência e } \\
\text { enfrentamento } \\
\text { de situações } \\
\text { adversas. }\end{array}$ \\
\hline $\begin{array}{l}\text { Soratto et } \\
\text { al., } 2016^{19} \\
\text { Qualitativo. }\end{array}$ & $\begin{array}{l}10 \text { pessoas, } \\
\text { com idade } \\
\text { entre } 35 \text { e } 77 \\
\text { anos. } \\
\text { Cânceres } \\
\text { mais } \\
\text { frequentes: } \\
\text { bexiga e } \\
\text { fígado. }\end{array}$ & $\begin{array}{l}\text { Medo do } \\
\text { sofrimento, } \\
\text { dor; e } \\
\text { desespero } \\
\text { familiar. }\end{array}$ & $\begin{array}{l}\text { Dificuldades } \\
\text { de adaptação } \\
\text { às limitações } \\
\text { impostas; } \\
\text { perda de } \\
\text { apetite, } \\
\text { náuseas, } \\
\text { vômitos, } \\
\text { feridas na } \\
\text { boca, alopecia. }\end{array}$ & $\begin{array}{l}\text { Acreditar em } \\
\text { Deus e ter fé } \\
\text { constituem a } \\
\text { espiritualida- } \\
\text { de, que possui } \\
\text { relação } \\
\text { positiva com a } \\
\text { resiliência. }\end{array}$ & $\begin{array}{l}\text { A fé remove } \\
\text { montanhas, } \\
\text { oferece força, } \\
\text { suporte e } \\
\text { sustentação. }\end{array}$ & $\begin{array}{l}\text { A esperança } \\
\text { de um futuro } \\
\text { melhor, e de } \\
\text { fase de doença } \\
\text { que vai passar, } \\
\text { aproximam os } \\
\text { conceitos } \\
\text { espiritualidade } \\
\text { e resiliência. }\end{array}$ \\
\hline $\begin{array}{l}\text { Miranda al., } \\
2015^{20} \\
\text { Quantitativo } \\
\text { e qualitativo, } \\
\text { com aplicação } \\
\text { de SWBS, BDI } \\
\text { e WHOQOL - } \\
\text { bref. }\end{array}$ & $\begin{array}{l}15 \text { pessoas, } \\
\text { com idade } \\
\text { predominante } \\
\text { entre } 41 \text { e } 60 \\
\text { anos. } \\
\text { Cânceres } \\
\text { mais } \\
\text { frequentes: } \\
\text { Mama, } \\
\text { ovário, } \\
\text { pulmão. }\end{array}$ & $\begin{array}{l}\text { Para } 87 \% \text { da } \\
\text { população } \\
\text { estudada, a fé } \\
\text { aumentou } \\
\text { após a } \\
\text { descoberta e } \\
\text { tratamento do } \\
\text { câncer. }\end{array}$ & $\begin{array}{l}\text { Perda e } \\
\text { afastamento } \\
\text { do emprego, } \\
\text { depressão, } \\
\text { aparência } \\
\text { física, cansaço, } \\
\text { preocupações } \\
\text { com a saúde, } \\
\text { educação dos } \\
\text { filhos, } \\
\text { problemas } \\
\text { financeiros, } \\
\text { alopecia, } \\
\text { mastectomia, } \\
\text { alterações do } \\
\text { sono. }\end{array}$ & $\begin{array}{l}\text { Quanto maior } \\
\text { bem-estar } \\
\text { religioso, } \\
\text { espiritual e } \\
\text { existencial, } \\
\text { maior a } \\
\text { qualidade de } \\
\text { vida. }\end{array}$ & $\begin{array}{l}\text { A relação } \\
\text { estabelecida } \\
\text { com a religião } \\
\text { pode ser } \\
\text { positiva ou } \\
\text { negativa. } \\
\text { Orientações } \\
\text { religiosas } \\
\text { podem levar } \\
\text { ao sentimento } \\
\text { de culpa ou } \\
\text { provação. }\end{array}$ & $\begin{array}{l}\text { A população } \\
\text { apresentou } \\
\text { bem-estar } \\
\text { espiritual e } \\
\text { religioso } \\
\text { moderados, o } \\
\text { que sugere } \\
\text { que o câncer } \\
\text { favorece a } \\
\text { busca pela } \\
\text { espiritualidade } \\
\text { e religiosidade } \\
\text { como fonte de } \\
\text { esperança de } \\
\text { cura. }\end{array}$ \\
\hline $\begin{array}{l}\text { Silva et al., } \\
2014^{11} \\
\text { Qualitativo. }\end{array}$ & $\begin{array}{l}44 \text { pessoas, } \\
\text { com idade } \\
\text { entre } 10 \text { e } \\
18 \text { anos. } \\
\text { Cânceres } \\
\text { mais } \\
\text { frequentes: } \\
\text { leucemia, } \\
\text { tumor do } \\
\text { SNC, linfoma. }\end{array}$ & $\begin{array}{l}\text { Desestrutu- } \\
\text { ração física, } \\
\text { emocional, } \\
\text { social e } \\
\text { espiritual por } \\
\text { conta de uma } \\
\text { série de } \\
\text { procedimen- } \\
\text { tos desconhe- } \\
\text { cidos e } \\
\text { dolorosos. }\end{array}$ & $\begin{array}{l}\text { Amadureci- } \\
\text { mento no } \\
\text { comportamen- } \\
\text { to familiar e } \\
\text { mudanças no } \\
\text { estilo de vida. } \\
\text { Comprometi- } \\
\text { mento das } \\
\text { atividades } \\
\text { diárias, } \\
\text { medidas de } \\
\text { percepção da } \\
\text { saúde e } \\
\text { medidas de } \\
\text { disfunção. }\end{array}$ & $\begin{array}{l}\text { Apego } \\
\text { espiritual e a fé } \\
\text { em Deus como } \\
\text { principal } \\
\text { auxiliador em } \\
\text { unanimidade. } \\
\text { A religião sai } \\
\text { do meio } \\
\text { apenas } \\
\text { cultural, se } \\
\text { tornando algo } \\
\text { prático, } \\
\text { motivacional. }\end{array}$ & $\begin{array}{l}\text { A fé é pilar de } \\
\text { sustentação ao } \\
\text { exercício da } \\
\text { espiritualida- } \\
\text { de, e permite } \\
\text { compreensão } \\
\text { de crenças e } \\
\text { valores, com } \\
\text { melhor } \\
\text { atendimento } \\
\text { das necessida- } \\
\text { des. }\end{array}$ & $\begin{array}{l}\text { A fé surgiu em } \\
\text { forma de } \\
\text { religião, crença } \\
\text { e cultura, que } \\
\text { consequente- } \\
\text { mente } \\
\text { transcendeu a } \\
\text { ideia apenas } \\
\text { de cura física. }\end{array}$ \\
\hline
\end{tabular}




\begin{tabular}{|c|c|c|c|c|c|c|}
\hline $\begin{array}{l}\text { Autores/Ano/ } \\
\text { Método }\end{array}$ & $\begin{array}{l}\text { População } \\
\text { do estudo }\end{array}$ & $\begin{array}{l}\text { Sentimentos e } \\
\text { afetações no } \\
\text { diagnóstico de } \\
\text { câncer }\end{array}$ & $\begin{array}{l}\text { Sentimentos e } \\
\text { afetações duran- } \\
\text { te o tratamento } \\
\text { do câncer }\end{array}$ & $\begin{array}{l}\text { A espiritualidad } \\
\text { e e a decisão pe- } \\
\text { lo enfrentamen- } \\
\text { to do câncer }\end{array}$ & $\begin{array}{l}\text { Ações } \\
\text { desenvolvidas } \\
\text { no campo } \\
\text { espiritual }\end{array}$ & $\begin{array}{l}\text { A espiritualidade } \\
\text { e a busca pela } \\
\text { cura }\end{array}$ \\
\hline $\begin{array}{l}\text { Caldeira et } \\
\text { al., 2014 } \\
\\
\text { Quantitativo } \\
\text { com } \\
\text { aplicação } \\
\text { de QBEE }\end{array}$ & $\begin{array}{l}45 \text { pessoas, } \\
\text { com idade } \\
\text { entre } 65 \text { e } 83 \\
\text { anos. } \\
\text { Cânceres } \\
\text { mais } \\
\text { frequentes: } \\
\text { mama, } \\
\text { intestino. }\end{array}$ & $\begin{array}{l}\text { Conteúdo não } \\
\text { abordado } \\
\text { neste artigo. }\end{array}$ & $\begin{array}{l}\text { Observou-se } \\
\text { que a } \\
\text { diminuição do } \\
\text { bem-estar } \\
\text { espiritual, } \\
\text { desesperança } \\
\text { e depressão } \\
\text { estavam } \\
\text { associadas ao } \\
\text { desejo de } \\
\text { morte rápida. }\end{array}$ & $\begin{array}{l}\text { Conteúdo não } \\
\text { abordado } \\
\text { neste artigo. }\end{array}$ & $\begin{array}{l}\text { A importância } \\
\text { da religião e } \\
\text { espiritualidade } \\
\text { foi muito } \\
\text { relevante para } \\
71,1 \% \text { dos } \\
\text { entrevistados. }\end{array}$ & $\begin{array}{l}\text { Conteúdo não } \\
\text { abordado } \\
\text { neste artigo. }\end{array}$ \\
\hline $\begin{array}{l}\text { Veit et al., } \\
2013^{22} \\
\text { Qualitativo. }\end{array}$ & $\begin{array}{l}7 \text { pessoas, } \\
\text { artigo não } \\
\text { informa } \\
\text { faixa etária. } \\
\text { Câncer de } \\
\text { mama. }\end{array}$ & $\begin{array}{l}\text { Medo, } \\
\text { angústia, } \\
\text { fé, A } \\
\text { compreensão } \\
\text { do surgimento } \\
\text { do câncer de } \\
\text { mama revelou } \\
\text { estar associada } \\
\text { a questões } \\
\text { religiosas / } \\
\text { espirituais. }\end{array}$ & $\begin{array}{l}\text { Destacou-se o } \\
\text { apoio social } \\
\text { recebido e foi } \\
\text { reconhecido } \\
\text { sua importân- } \\
\text { cia no } \\
\text { processo de } \\
\text { tratamento. }\end{array}$ & $\begin{array}{l}\text { Fortalecimen- } \\
\text { to e amparo } \\
\text { através da fé } \\
\text { em Deus. } \\
\text { A presença do } \\
\text { estilo coping } \\
\text { religioso / } \\
\text { espiritual } \\
\text { colaborativo } \\
\text { estabelece } \\
\text { parceria com } \\
\text { Deus na } \\
\text { resolução de } \\
\text { problemas. }\end{array}$ & $\begin{array}{l}\text { O diálogo com } \\
\text { Deus objetivou } \\
\text { busca por } \\
\text { respostas e } \\
\text { paz, e } \\
\text { proporcionava } \\
\text { diminuição de } \\
\text { emoções } \\
\text { negativas. }\end{array}$ & $\begin{array}{l}\text { Perspectiva de } \\
\text { que Deus tem } \\
\text { um plano para } \\
\text { cada ser } \\
\text { humano e que } \\
\text { tudo acontece } \\
\text { com algum } \\
\text { propósito. } \\
\text { A relação do } \\
\text { poder de Deus } \\
\text { e a cura foi } \\
\text { certeza para } \\
\text { todas as } \\
\text { participantes. }\end{array}$ \\
\hline $\begin{array}{l}\text { Furlan et al., } \\
2012^{5} \\
\text { Qualitativo. }\end{array}$ & $\begin{array}{l}3 \text { pessoas, } \\
\text { com } 49,55 \\
\text { e } 62 \text { anos. } \\
\text { Câncer de } \\
\text { mama. }\end{array}$ & $\begin{array}{l}\text { Conteúdo não } \\
\text { abordado } \\
\text { neste artigo. }\end{array}$ & $\begin{array}{l}\text { O conforto } \\
\text { pelo apoio } \\
\text { social e } \\
\text { suporte da } \\
\text { família, de } \\
\text { amigos, e } \\
\text { serviço de } \\
\text { saúde foram } \\
\text { indispensáveis } \\
\text { ao processo de } \\
\text { tratamento e } \\
\text { recuperação } \\
\text { da saúde. }\end{array}$ & $\begin{array}{l}\text { Suporte de } \\
\text { líderes e } \\
\text { membros } \\
\text { religiosos, } \\
\text { promovem } \\
\text { aproximação } \\
\text { com a } \\
\text { espiritualida- } \\
\text { de, com } \\
\text { conselhos e } \\
\text { orações. }\end{array}$ & $\begin{array}{l}\text { A fé e a } \\
\text { esperança } \\
\text { podem ajudar } \\
\text { a aliviar a dor e } \\
\text { sofrimento } \\
\text { causados pela } \\
\text { presença da } \\
\text { doença em seu } \\
\text { cotidiano. } \\
\text { Conselhos e } \\
\text { orações. }\end{array}$ & $\begin{array}{l}\text { A religião / } \\
\text { espiritualidade } \\
\text { auxiliam nas } \\
\text { questões } \\
\text { relativas a } \\
\text { esperança } \\
\text { relacionada à } \\
\text { cura. }\end{array}$ \\
\hline $\begin{array}{l}\text { Guerreiro et al., } \\
2011^{23} \\
\text { Qualitativo. }\end{array}$ & $\begin{array}{l}14 \text { pessoas, } \\
\text { com idade } \\
\text { entre } 23 \text { e } \\
72 \text { anos. } \\
\text { Cânceres } \\
\text { mais } \\
\text { frequentes: } \\
\text { mama, } \\
\text { sarcoma, } \\
\text { leucemia, } \\
\text { mieloma. }\end{array}$ & $\begin{array}{l}\text { Perplexidade, } \\
\text { tristeza, } \\
\text { angústia, } \\
\text { indignação, } \\
\text { sofrimento, e } \\
\text { medo da } \\
\text { morte. }\end{array}$ & $\begin{array}{l}\text { O alívio do } \\
\text { sofrimento } \\
\text { acontece na } \\
\text { medida em } \\
\text { que a fé } \\
\text { religiosa } \\
\text { permite } \\
\text { transfor- } \\
\text { mações na } \\
\text { perspectiva } \\
\text { pela qual o } \\
\text { paciente e a } \\
\text { comunidade } \\
\text { percebem a } \\
\text { doença grave. }\end{array}$ & $\begin{array}{l}\text { Foram citadas } \\
\text { a fé, a crença } \\
\text { em Deus, a } \\
\text { importância da } \\
\text { religião e o } \\
\text { pensamento } \\
\text { positivo. }\end{array}$ & $\begin{array}{l}\text { Ênfase na } \\
\text { busca por } \\
\text { Deus, orações, } \\
\text { percepção do } \\
\text { crescimento } \\
\text { relacionado à } \\
\text { relação com } \\
\text { Deus e fé em } \\
\text { seu poder. }\end{array}$ & $\begin{array}{l}\text { Na perspectiva } \\
\text { do paciente, } \\
\text { Deus tem o } \\
\text { poder para } \\
\text { fazer todas as } \\
\text { coisas, e como } \\
\text { a cura do } \\
\text { câncer ainda } \\
\text { não tem sua } \\
\text { totalidade na } \\
\text { ciência da } \\
\text { saúde, buscam } \\
\text { por } \\
\text { intervenção } \\
\text { divina. }\end{array}$ \\
\hline $\begin{array}{l}\text { Spadacio et al., } \\
2009^{24} \\
\text { Qualitativo. }\end{array}$ & $\begin{array}{l}8 \text { pessoas, } \\
\text { com idade } \\
\text { entre } 36 \mathrm{e} \\
75 \text { anos. } \\
\text { Artigo não } \\
\text { aborda tipo } \\
\text { de câncer. }\end{array}$ & $\begin{array}{l}\text { Conteúdo não } \\
\text { abordado } \\
\text { neste artigo. }\end{array}$ & $\begin{array}{l}\text { A religião } \\
\text { colaborou no } \\
\text { tratamento } \\
\text { proporcionan- } \\
\text { do tranquilida- } \\
\text { de através da } \\
\text { fé. }\end{array}$ & $\begin{array}{l}\text { O recurso } \\
\text { religioso foi } \\
\text { prática } \\
\text { terapêutica de } \\
\text { cura, crucial } \\
\text { para o sucesso } \\
\text { no tratamento } \\
\text { convencional e } \\
\text { superação da } \\
\text { doença. }\end{array}$ & $\begin{array}{l}\text { Os caminhos } \\
\text { religiosos } \\
\text { percorridos } \\
\text { encontram-se } \\
\text { em conformi- } \\
\text { dade com as } \\
\text { especificida- } \\
\text { des de cada } \\
\text { religião. }\end{array}$ & $\begin{array}{l}\text { Conteúdo não } \\
\text { abordado } \\
\text { neste artigo. }\end{array}$ \\
\hline
\end{tabular}




\begin{tabular}{|c|c|c|c|c|c|c|}
\hline $\begin{array}{l}\text { Autores/Ano/ } \\
\text { Método }\end{array}$ & $\begin{array}{l}\text { População } \\
\text { do estudo }\end{array}$ & $\begin{array}{l}\text { Sentimentos e } \\
\text { afetações no } \\
\text { diagnóstico de } \\
\text { câncer }\end{array}$ & $\begin{array}{l}\text { Sentimentos e } \\
\text { afetações duran- } \\
\text { te o tratamento } \\
\text { do câncer }\end{array}$ & $\begin{array}{l}\text { A espiritualidad } \\
\text { e e a decisão pe- } \\
\text { lo enfrentamen- } \\
\text { to do câncer }\end{array}$ & $\begin{array}{l}\text { Ações } \\
\text { desenvolvidas } \\
\text { no campo } \\
\text { espiritual }\end{array}$ & $\begin{array}{l}\text { A espiritualidade } \\
\text { e a busca pela } \\
\text { cura }\end{array}$ \\
\hline $\begin{array}{l}\text { Teixeira et al., } \\
2008^{25} \\
\text { Qualitativo. }\end{array}$ & $\begin{array}{l}20 \text { pessoas, } \\
\text { com idade } \\
\text { entre } 60 \text { e } \\
87 \text { anos. } \\
\text { Artigo não } \\
\text { aborda tipo } \\
\text { de câncer. }\end{array}$ & $\begin{array}{l}\text { Conteúdo não } \\
\text { abordado } \\
\text { neste artigo. }\end{array}$ & $\begin{array}{l}\text { Medo, efeitos } \\
\text { adversos, } \\
\text { experiências } \\
\text { negativas } \\
\text { prévias e o } \\
\text { desejo por } \\
\text { mais cuidados } \\
\text { de apoio } \\
\text { levam } \\
\text { pacientes à } \\
\text { busca por } \\
\text { tratamentos } \\
\text { alternativos. }\end{array}$ & $\begin{array}{l}\text { Pessoas com } \\
\text { forte fé } \\
\text { religiosa } \\
\text { podem } \\
\text { redefinir } \\
\text { eventos } \\
\text { negativos em } \\
\text { sua vida, como } \\
\text { uma oportuni- } \\
\text { dade de } \\
\text { crescimento } \\
\text { espiritual ou } \\
\text { como parte de } \\
\text { um plano } \\
\text { divino mais } \\
\text { amplo. }\end{array}$ & $\begin{array}{l}\text { Pregações de } \\
\text { casa em casa, } \\
\text { que auxiliam a } \\
\text { relaxar, distrair } \\
\text { e melhor } \\
\text { aceitar } \\
\text { desafios. }\end{array}$ & $\begin{array}{l}\text { Muitas pessoas } \\
\text { veem na fé um } \\
\text { "remédio" } \\
\text { muito } \\
\text { poderoso para } \\
\text { o seu restabe- } \\
\text { lecimento. }\end{array}$ \\
\hline
\end{tabular}

Em relação aos sentimentos no momento do diagnóstico, é possível observar que a desestruturação emocional foi citada em maior número de vezes, e compreenderam sentimentos negativos, relatados pelo paciente frente ao diagnóstico do câncer. Em seguida, a desestruturação espiritual também foi relatada pelos pacientes, que frente a vivência de situação adversa, constrói elos entre a doença no plano físico e a fé. A desestruturação física e desestruturação social também foram citadas na interferência experimentada pela situação do diagnóstico de câncer. Contudo, a maioria dos artigos selecionados não abordaram esse conteúdo na explanação sobre o câncer e os pacientes.

Durante o tratamento do câncer, vários sentimentos e afetações foram citados, sendo observado a grande preocupação com as alterações na aparência física, seguido do uso da fé como promotora de alívio frente ao sofrimento imposto.

No enfrentamento do câncer, a espiritualidade constituiu importante fator contribuidor para decisão e manutenção do enfrentamento. A fé em Deus, com ênfase ao apego espiritual, gerou força, amparo e esperança aos pacientes, que afirmaram maior garra e disposição para este enfrentamento.

Com vistas à importância da espiritualidade na vida de pacientes com câncer, outra questão se relacionou a explanar as formas de enfrentamento que são efetuadas no campo espiritual, e neste ponto, o alívio do sofrimento por meio da fé, e a compreensão de significados às experiências de vida foram citadas.

Dentre as ações, propriamente ditas, que são desenvolvidas no campo espiritual, a oração foi a mais frequente, onde o diálogo com Deus se traduziu em importante meio para aquisição de forças para o enfrentamento e alívio de sentimentos relacionados a condição de vivenciar o câncer.

\section{Discussão}

Com o desenvolvimento deste estudo, pudemos notar que existem poucos artigos que abordam a questão espiritual, conforme a percepção do paciente com câncer, mesmo com as inú- 
meras discussões acerca da integralidade de visão holística necessária ao cuidado em saúde do ser humano.

O impacto causado na ocorrência do diagnóstico do câncer é grande, e como estratégia de enfrentamento, existe um predomínio importante em grande parte da população relacionado as questões religiosas e espirituais ${ }^{7}$.

Com isso, a abordagem dessa temática se torna essencial, e deve ser norteadora dos cuidados, desde a procura, pelo paciente, dos serviços de saúde e início de realização de exames diagnósticos, passando pelo tratamento e a cura, ou cuidados paliativos.

Em uma visão geral, os autores exaltam a importância da religiosidade e espiritualidade na vida de pacientes com câncer, e como o uso desse instrumento pode ser uma importante estratégia de enfrentamento frente a essa situação.

O diagnóstico de câncer pode trazer sentimento de culpa, tristeza, fracasso, perda da autoestima, incerteza, ansiedade, depressão, nervosismo, medo, preocupação e insegurança quanto aos futuros acontecimentos ${ }^{26-29}$.

A desestruturação emocional foi de maior impacto na vida dos pacientes, e estes relataram sentimentos como medo, angústia, perplexidade frente a situação, tristeza, indignação e estado de choque. Sentimentos esses que são relatados em vários artigos, já citados em parágrafo anterior, onde outros pacientes, na mesma condição, vivenciaram um importante impacto emocional.

A busca pela espiritualidade se intensifica à medida que o contato do paciente com o câncer se torna real, pois o estigma do sofrimento, da angústia e do medo, gerados pela incerteza do futuro, ainda são significados atribuídos ao câncer ${ }^{23}$.

O estresse, a tensão, conflitos espirituais, conflitos emocionais e as incertezas são sentimentos comuns às pessoas que vivenciam o câncer, e caracterizam um processo doloroso com grandes possibilidades de causar desestrutura por consequência do impacto negativo causado pelo diagnóstico, e da imposição de mudanças na rotina diária e do medo da morte ${ }^{11,20}$.

Quanto a desestruturação da fé, os relatos foram correspondentes a um aumento e aproximação com as questões relacionadas a espiritualidade e às questões religiosas, com afirmações de que essa aproximação gerou sentimento de aumento da fé em Deus.

Na perspectiva do paciente, a relação entre a espiritualidade e o câncer é a de que o câncer produz o medo, enquanto que a espiritualidade produz a renovação ${ }^{23}$.

A busca pela compreensão do sentido da vida é intensificada frente a hostilidade característica da doença e do ambiente clínico, e nesse sentido, gerar força interior que dê suporte no enfrentamento da doença produz aproximação do indivíduo com a espiritualidade, culminando em aumento da fé.

A fé, quando desenvolvida na vida das pessoas, evidencia a importância da espiritualidade e a existência de uma relação entre elas e o poder divino. Na elaboração do significado para a experiência do câncer, a fé favorece maior controle da doença e mobilização de senso de esperança 
relacionado à cura ${ }^{22}$. Principalmente em momentos de crise e/ou adoecimento, a fé se manifesta de forma essencial à existência do ser humano, como que de forma inseparável, surgindo de forma arraigada ao ser ${ }^{14}$.

No decorrer do tratamento do câncer, vários sentimentos podem surgir na vida dos pacientes, além da vivência de experiências que afetam os mesmos de forma significativa. Nesta revisão, os sentimentos e afetações de aspecto positivo compreendem o fortalecimento pela fé, alívio do sofrimento pela fé, reconhecimento do apoio social como fator de proteção e alívio, e sentimento de amadurecimento. Os de aspecto negativo englobam o comprometimento das atividades diárias, preocupações com a saúde física, cansaço físico, alterações na aparência física, desejo de morte rápida, depressão, e problemas financeiros, que pode ser em decorrência da perda da fonte de renda.

Sentimentos de incerteza e ameaça à vida são frequentes em pacientes com câncer, e podem culminar em deficiências no bem-estar psicossocial ${ }^{30}$.

Em mulheres, os sentimentos e afetações relacionados ao câncer abrangem uma vasta gama de fatores físicos, psicológicos, sociais, cognitivos, existenciais e/ou sexuais. Sobre esses sentimentos e afetações, cita-se as preocupações constantes relacionadas a recaída e disseminação do câncer, incerteza sobre o futuro, problemas psicológicos relacionados com a sexualidade e infertilidade e a necessidade de informação sobre a doença. Os sintomas ainda poderão existir em consequência da própria doença ou de seu tratamento, podendo persistir a longo prazo ${ }^{31}$.

Os sentimentos vivenciados podem ser percebidos e avaliados como sofrimentos, e para estes, definições variadas são encontradas conforme o modo de vida e o estágio em que se encontra a doença. Dentre as definições de sofrimento descritas por pacientes com câncer, permite-se citar o sofrimento inevitável e evitável, sofrimento físico e emocional, sofrimento como a perda e a transformação através do sofrimento ${ }^{32}$.

A transformação ocorrida na vida de pessoas com câncer se relaciona com a espiritualidade em alguns momentos, sendo creditada a ela e a esta experiência um novo modo de viver e conceituar a vida e as relações.

A espiritualidade assume importante significado na vida dos pacientes com câncer, em relação ao enfrentamento da doença. Na análise da relação entre a espiritualidade e o enfrentamento do câncer, as ocorrências são baseadas no apego espiritual, na fé em Deus, na manutenção da esperança por meio da fé, sentimento de aumento de força, amparo e esperança, no significado que a religião passa a ter na vida das pessoas, deixando de ser somente algo cultural, na importância e influência de líderes e membros religiosos e o apoio prestado pelos mesmos, no pensamento positivo, na utilização da espiritualidade como prática terapêutica de cura e na visão da doença como oportunidade de crescimento espiritual.

A religiosidade e a espiritualidade, em casos de situações consideradas difíceis como no diagnóstico e tratamento do câncer, podem se constituir como importantes estratégias de enfrentamento, pois aparecem como fontes de conforto e esperança diante de um momento desafiador ${ }^{33}$.

O benefício proporcionado, em termo de melhoria de qua-

A transformação ocorrida na vida de pessoas com câncer se relaciona com a espiritualidade em alguns momentos, sendo creditada a ela e a esta experiência um novo modo de viver e conceituar a vida e as relações. 
lidade de vida, após intervenções espirituais com pacientes com câncer, foi observado quando comparados a um grupo controle ${ }^{34}$.

Ainda, os benefícios das crenças espirituais podem ser associados a maior satisfação de tomada de decisões, menor conflito e dificuldade no processo de tomada de decisão em homens com câncer de próstata. Neste estudo, quando maior a espiritualidade, maior foi a satisfação de tomada de decisão, e menor a dificuldade de decisão. Dessa forma, a possibilidade da redução da incerteza e do estresse que acompanham o paciente com câncer em suas percepções sobre diagnóstico e tratamento podem ocorrer de forma a integrar as suas crenças como instrumento auxiliador ${ }^{35}$.

No campo espiritual, o enfrentamento do câncer se dá de diversas formas. As principais formas de enfrentamento do câncer compreenderam a compreensão de crenças e valores, significado às experiências de vida, ato de ouvir a voz de Deus por meio de pessoas, sentimento de alívio da dor e do sofrimento por meio da fé em Deus, e, por outro lado, também houveram relatos e comportamentos de negação da doença, e entendimento da experiência da doença como processo de provação ou de culpa por atos considerados errados, porém já realizados em vida.

Ainda no campo espiritual, sobre as ações que são desenvolvidas pelos pacientes, observa-se a oração, como mais frequente prática religiosa e espiritual realizada, seguida de conselhos e pregações, ênfase na busca por Deus, cirurgia espiritual, meditação e cromoterapia. A busca pela cura através da espiritualidade foi ato realizado frequentemente. Devido à incerteza e medo gerados pela cultura social sobre o câncer, o apego espiritual pode ser evidenciado e enfatizado ao vivenciar a experiência desta doença.

A espiritualidade, em pacientes com câncer, é expressada conforme a esperança de cura, permitindo a observação da ocorrência de uma ligação positiva entre a crença espiritual e o enfrentamento do câncer. Dessa forma, o paradigma de que o câncer é uma doença incurável é quebrado através da fé, que proporciona novo sentido de vida ao indivíduo, e comporta-se como importante aliado no enfrentamento deste contra o câncer ${ }^{36}$.
O paradigma de que o câncer é uma doença incurável é quebrado através da fé, que proporciona novo sentido de vida ao indivíduo, e comportase como importante aliado no enfrentamento deste contra o câncer.

Contudo, o sentimento de amadurecimento e melhor compreensão da vida e do sentido da mesma proporcionaram que a busca da cura através da fé não fosse limitada ao plano físico, mas se expandiu ao plano espiritual.

Também foi possível analisar que os pacientes passaram a se sentirem mais fortes e aliviados quando desenvolveram a visão e entendimento de que Deus tem o controle de todas as coisas, e um plano para a vida de cada pessoa, assim, a esperança de um futuro bom se fez presente de forma satisfatória.

Importante notar também que para todos os artigos, os entrevistados afirmaram convicção do poder de Deus de forma soberana.
Foi possível analisar que os pacientes passaram a se sentirem mais fortes e aliviados quando desenvolveram a visão e entendimento de que Deus tem o controle de todas as coisas, e um plano para a vida de cada pessoa, assim, a esperança de um futuro bom se fez presente de forma satisfatória. 
A sensação de refrigério é muito importante ao paciente oncológico, devido ao estado de vulnerabilidade a pensamentos solitários e solidão, contudo, a figura de Deus como alguém próximo, acessível, protetor e cuidador, gera uma sensação de bem-estar espiritual tamanha que proporciona ao indivíduo sentimento de ser alguém especial, único e insubstituível ${ }^{36}$.

\section{Conclusão}

O paciente com câncer que vivencia a espiritualidade como instrumento terapêutico é independente de sexo, idade, classe social, raça e religião, sendo que a afirmação da importância do apego espiritual se mostrou de forte impacto positivo na vida destes pacientes.

Os sentimentos e afetações na vida de pessoas com câncer são vários, sendo observado a fé como fator de proteção, alívio de sofrimento e esperança de cura, e quanto maior o envolvimento dessas pessoas com as questões espirituais, melhor será a qualidade de vida que terão mesmo em meio ao desafio da doença e dos agravos causados por ela.

O comportamento de pacientes com câncer, no que tange a relação com a espiritualidade, é observado como algo de muita importância, e que gera alívio e desejo de seguir as recomendações para o tratamento completo. De fato, os artigos selecionados evidenciam um forte elo entre a fé e a esperança de cura, além da compreensão dos modos de vida e entendimento sobre as experiências impostas em seu decorrer.

Com este estudo, espera-se que a observação sobre a espiritualidade na vida dos pacientes de forma essencial, evidenciando a necessidade de harmonia no tratamento entre o plano físico e o plano espiritual, incorporando práticas científicas e a fé dos pacientes, a fim de que a adesão ao tratamento seja maior e seja facilitada.

Declaração de conflito de interesses: $O$ autor declara não ter nenhum conflito de interesses.

\section{Referências}

1. Bray F, Ferlay J, Soerjomataram I, Siegel RL, Torre LA, Jemal A. Global Cancer Statistics 2018: GLOBOCAN Estimates of Incidence and Mortality Worldwide for 36 Cancers in 185 Countries. CA Cancer J. Clin. 2018;68:394-424. https://doi.org/10.3322/caac.214922

2. Instituto Nacional de Câncer José Alencar Gomes da Silva. Coordenação de Prevenção e Vigilância. Estimativa 2016: incidência de câncer no Brasil. Rio de Janeiro: INCA, 2015.

3. Instituto Nacional de Câncer José Alencar Gomes da Silva. Coordenação de Prevenção e Vigilância. Estimativa 2018: incidência de câncer no Brasil. Rio de Janeiro: INCA, 2017.

4. Instituto Nacional de Câncer José Alencar Gomes da Silva. ABC do câncer: abordagens básicas para o controle do câncer. Rio de Janeiro: INCA, 2019.

5. Furlan MCR, Bernardi J, Vieira AM, Santos MCC, Marcon SS. Percepção de mulheres submetidas à mastectomia sobre o apoio social. Ciência, Cuidado e Saúde. 2012;11(1):66-73. https://doi.org/10.4025/cienccuidsaude.v11i1.18860

6. Silva MR, Paraíba M. Câncer: uma abordagem psicológica. Porto Alegre: AGE; 2008.

7. Fornazari SA, Ferreira RER. Religiosidade/espiritualidade em pacientes oncológicos: qualidade de vida e saúde. Psic.: Teor. e Pesq. 2010;26(2):265-72.

https://doi.org/10.1590/S0102-37722010000200008 
8. Chaves ECL, Carvalho EC, Hass VJ. Validação do diagnóstico de enfermagem Angústia Espiritual: análise por especialistas. Acta paul. enferm. [online]. 2010;23(2):264-70. https://doi.org/10.1590/S0103-21002010000200018

9. Thiengo PCS, Gomes AMT, Mercês MC, Couto PLS, França LCM, Silva AN. Espiritualidade e religiosidade no cuidado em saúde: revisão integrativa. Cogitare enferm. 2019; 24: e58692. https://doi.org/10.5380/ce.v24i0.58692

10. Kübler-Ross E. Sobre a morte e o morrer. São Paulo: Editora WMF Martins Fontes, 2008.

11. Silva GM, Kameo SY, Sawada NO. Percepções da criança e do adolescente com câncer frente ao diagnóstico e tratamento da doença. Rev. iberoam. educ. invest. enferm. 2014;4(4):1524.

12. Oliveira JM, Reis JB, Silva RA. Busca por cuidado oncológico: percepção de pacientes e familiares. Rev enferm UFPE on line. 2018;12(4):938-46.

https://doi.org/10.5205/1981-8963-v12i4a231359p938-946-2018

13. Ferrão L, Bettinelli LA, Portella MR. Vivências de homens com câncer de próstata. Rev enferm UFPE on line. 2017;11(Supl.10):4157-64.

https://doi.org/10.5205/reuol.10712-95194-3-SM.1110sup201720

14. Pereira J. A fé como fenômeno psicológico. São Paulo: Escrituras Editora; 2016.

15. Silva CF, Borges FR, Avelino CCV, Miarelli AVTC, Vieira GIA, Goyatá SLT. Espiritualidade e religiosidade em pacientes com hipertensão arterial sistêmica. Rev. Bioét. 2016;24(2):332-43. https://doi.org/10.1590/1983-80422016242134

16. Benites AC, Neme CMB, Santos MA. Significados da espiritualidade para pacientes com câncer em cuidados paliativos. Estudos de Psicologia. 2017;34(2):269-79. https://doi.org/10.1590/1982-02752017000200008

17. Souza MT, Silva MD, Carvalho R. Revisão integrativa: o que é e como fazer. Einstein (São Paulo). 2010;8(1):102-6. https://doi.org/10.1590/s1679-45082010rw1134

18. Menezes RR, Kameo SY, Valença TS, Mocó GAA, Santos JMJ. Qualidade de Vida Relacionada à Saúde e Espiritualidade em Pessoas com Câncer. Rev. bras. cancerol. 2018;64(1):9-17. https://doi.org/10.32635/2176-9745.RBC.2018v64n1.106

19. Soratto MT, Silva DM, Zugno PI, Daniel R. Espiritualidade e resiliência em pacientes oncológicos. Revista Saúde e Pesquisa. 2016; 9(1): 53-63. https://doi.org/10.17765/1983-1870.2016v9n1p53-63

20. Miranda SL, Lanna MAL, Felippe WC. Espiritualidade, Depressão e Qualidade de Vida no Enfrentamento do Câncer: Estudo Exploratório. Psicol. cienc. prof. [online]. 2015;35(3):870-85. https://doi.org/10.1590/1982-3703002342013

21. Caldeira S, Carvalho EC, Vieira M. Entre o bem-estar espiritual e a angústia espiritual: possíveis fatores relacionados a idosos com cancro. Rev. Latino-Am. Enfermagem. 2014;22(1):2834. https://doi.org/10.1590/0104-1169.3073.2382

22. Veit CM, Castro EK. Coping religioso/espiritual positivo em mulheres com câncer de mama: um estudo qualitativo. Psico. 2013;44(3):331-41.

23. Guerrero GP, Zago MMF, Sawada NO, Pinto MH. Relação entre espiritualidade e câncer: perspectiva do paciente. Rev. bras. enferm. 2011;64(1):53-9.

https://doi.org/10.1590/S0034-71672011000100008

24. Spadacio C, Barros NF. Terapêuticas convencionais e não convencionais no tratamento do câncer: os sentidos das práticas religiosas. Interface (Botucatu) [online]. 2009;13(30):45-52. https://doi.org/10.1590/S1414-32832009000300005

25. Teixeira JJC, Lefèvre F. Significado da intervenção médica e da fé religiosa para o paciente idoso com câncer. Ciênc. saúde coletiva [online]. 2008;13(4):1247-56.

https://doi.org/10.1590/S1413-81232008000400021 
26. Ribeiro VC, Portella VSDC, Malheiro VES. Mulheres de meia idade e o enfrentamento do câncer de mama. Rev Cuid. 2014;5(2):799-805. https://doi.org/10.15649/cuidarte.v5i2.120

27. Nascimento KTS, Fônseca LCT, Andrade SSC, Leite KNS, Costa TF, Oliveira SHS. Sentimentos e fontes de apoio emocional de mulheres em pré-operatório de mastectomia em um hospital-escola. Revista Enfermagem UERJ. 2015;23(1):108-14.

https://doi.org/10.12957/reuerj.2015.15598

28. Oshiro ML, Bergmann A, Silva RG, Costa KC, Travaim IEB, et al. Câncer de mama avançado como evento sentinela para avaliação do programa de detecção precoce do câncer de mama no Centro-Oeste do Brasil. Rev. bras. cancerol. 2014;60(1):15-23. https://doi.org/10.32635/2176-9745.RBC.2014v60n1.488

29. Porto SM, Carvalho GB, Fernandes MJM, Ferreira CB. Vivências de homens frente ao diagnóstico de câncer de próstata. Ciência \& Saúde. 2016;9(2):83-9. https://doi.org/10.15448/1983-652X.2016.2.22225

30. Peh CX, Kua EH, Mahendran R. Hope, emotion regulation, and psychosocial well-being in patients newly diagnosed with cancer. Support Care Cancer. 2016;24(5):1955-1962. https://doi.org/10.1007/s00520-015-2989-x

31. Holt KA, Mogensen O, Jensen PT, Hansen DG. Goal setting in cancer rehabilitation and relation to quality of life among women with gynaecological cancer. Acta Oncol. 2015;54(10):1814-23. https://doi.org/10.3109/0284186X.2015.1037009

32. Ellis J, Cobb M, O'Connor T, Dunn L, Irving G, Lloyd-Williams M. The meaning of suffering in patients with advanced progressive cancer. Chronic IIIn. 2015;11(3):198-209. https://doi.org/10.1177/1742395314565720

33. Alves DA, Silva LG, Delmondes GA, Lemos ICS, Kerntopf MR, Albuquerque GA. Cuidador de criança com câncer: religiosidade e espiritualidade como mecanismos de enfrentamento. Rev Cuid. 2016;7(2):1318-24. https://doi.org/10.15649/cuidarte.v7i2.336

34. Kruizinga R, Hartog ID, Jacobs M, Daams JG, Scherer-Rath M, Schilderman JB, et al. The effect of spiritual interventions addressing existential themes using a narrative approach on quality of life of cancer patients: a systematic review and meta-analysis. Psychooncology. 2016;25(3):253-65. https://doi.org/10.1002/pon.3910

35. Mollica MA, Underwood W, Homish GG, Homish DL, Orom H. Spirituality is associated with better prostate cancer treatment decision making experiences. J Behav Med. 2016;39(1):1619. https://doi.org/10.1007/s10865-015-9662-1

36. Cardoso AHA. Espiritualidade e câncer em pacientes submetidos a tratamento quimioterápico [monografia]. Campina Grande: Universidade Estadual da Paraíba; 2014. 